\title{
Pharmacological management of spasticity in Multiple Sclerosis: systematic review and consensus paper.
}

Susana Otero-Romero ${ }^{1,2}$, Jaume Sastre-Garriga ${ }^{1}$, Giancarlo Comi ${ }^{3}$, Hans-Peter

Hartung ${ }^{4}$, Per Soelberg Sørensen ${ }^{5}$, Alan J Thompson ${ }^{6}$, Patrick Vermersch ${ }^{7}$, Ralf Gold ${ }^{8}$, Xavier Montalban ${ }^{1}$.

1. Multiple Sclerosis Centre of Catalonia (Cemcat), Department of Neurology-Neuroimmunology, Vall d'Hebron University Hospital, Barcelona, Spain.

2. Preventive Medicine and Epidemiology Department Vall d'Hebron University Hospital, Barcelona, Spain.

3. Neurological Department, Institute of Experimental Neurology (INSPE), Scientific Institute Hospital San Raffaele, University Vita-Salute San Raffaele, Milan, Italy.

4. Department of Neurology, Medical Faculty, Multiple Sclerosis, Heinrich-Heine-University, Düsseldorf, Germany.

5. Danish Multiple Sclerosis Center, Department of Neurology, Copenhagen University Hospital Rigshospitalet, Denmark.

6. Department of Brain Repair and Rehabilitation, University College London Institute of Neurology, Faculty of Brain Sciences, London, UK.

7. Univ. Lille, INSERM, CHU Lille, U995 -LIRIC-Lille Inflammation Research International Center, F59000 Lille, France.

8. Department of Neurology, Ruhr University, St Josef-Hospital, Bochum, Germany.

\section{Corresponding author}

Dr. Susana Otero-Romero

Mailing address:

Edifici Antiga EUI, pl. Baixa. Hospital Universitari Vall d'Hebron

Pg. Vall d'Hebron, $119-129$

08035 Barcelona (Spain)

E-mail: susana.otero@epidemcat.cat

Tel: (+34) 934894237

Fax: (+34) 934894111

Key words: Multiple sclerosis, spasticity, pharmacological treatment, review. 


\begin{abstract}
Background and objectives: Treatment of spasticity poses a major challenge resulting from its complex clinical presentation and the variable efficacy and safety profiles of available drugs. We present a systematic review of the pharmacological treatment of spasticity in MS patients.

Methods: Controlled trials and observational studies were identified using MEDLINE and Cochrane databases. Scientific evidence was evaluated according to pre-specified levels of certainty. Practical considerations are provided for the different interventions considered.
\end{abstract}

Results: The evidence supports the use of baclofen, tizanidine and gabapentin as first line options for MS patients with spasticity. Diazepam or dantrolene could be considered if no clinical improvement is seen with the previous drugs. Nabiximols has a positive effect when used as add-on therapy in patients with suboptimal response or poor tolerance to first-line oral treatments. Despite methodological limitations in trials supporting their use, intrathecal baclofen and intrathecal phenol appear to show a positive effect in patients with severe spasticity and sub-optimal response to oral drugs. Local application of botulinum toxin or phenol injections can be beneficial in focal spasticity.

Conclusions: The available studies on spasticity treatment offer some insight to guide clinical practice, but are of variable methodological quality. Large, well-designed trials with better assessment tools are needed to confirm the effectiveness of antispasticity agents and to inform the design of evidence-based treatment algorithms. 


\section{BACKGROUND}

Spasticity results from damage to the upper motor neurons of the corticospinal tract with abnormal supraspinal driving of spinal reflexes, and affects around $34 \%$ of multiple sclerosis (MS) patients. ${ }^{1}$ It is characterized by increased muscle tone caused by hyperexcitability of the stretch reflex. It is often accompanied by weakness, pain and involuntary sudden movements (spasms) and, if severe, with contractures. ${ }^{2}$ Patients with spasticity may exhibit worsening of symptoms in the setting of underlying infection, such as urinary tract infections, or other noxious stimuli. ${ }^{3}$

Different outcome measures are used to evaluate the degree of spasticity and its interference with function, including physician and patient-based scales. ${ }^{4}$ The most widely used is the (modified) Ashworth scale, which provides a semi-quantitative measure of the resistance to passive movement graded from 0 to 5 , as perceived by the examiner. Other scales in use are the (modified) Tardieu scale ${ }^{5}$; the Priebe and Penn scale $^{6}$ and self-reported scales such as the Visual Analogue Scale, the Numeric Rating Scale or the Multiple Sclerosis Spasticity Scale (MSSS-88) ${ }^{7}$ which can address stiffness, clonus, spasms, pain and overall comfort. More complex techniques including the Wartenberg Pendulum tests, gait analysis or electromyography tend to be reserved for research purposes. ${ }^{8}$

Optimum management of spasticity requires a multidisciplinary team (physiotherapist, nurse, neurologist, rehabilitation physician) and regular follow up. ${ }^{9}$ The goal of therapy is to increase functional capacity, facilitate rehabilitation, prevent contractures and relieve pain. The approach is usually multimodal, combining non-pharmacological and 
pharmacological interventions. ${ }^{10}$ An evaluation of the scientific evidence regarding physical therapy is beyond the scope of this review and detailed information can be found elsewhere. ${ }^{11}$

We aimed to (i) review the current literature involving pharmacological treatment of spasticity, (ii) offer advice on best use of available agents based on the evidence and the consensus of the expert authors and (iii) identify methological limitations in the available evidence. 


\section{METHODS (search strategy and consensus)}

Evidence was collected by searches for systematic reviews, meta-analyses and original articles in MEDLINE and Cochrane databases before August 2013, using the search terms "multiple sclerosis", "spasticity", "spasm", "muscular rigidity", and their combinations, as well as abbreviations for the selected interventions (oral baclofen, tizanidine, dantrolene, benzodiazepines, gabapentin, cannabis-based drugs, botulinum toxin $\mathrm{A}$, intrathecal baclofen and phenol injections). Additionally, the references of evaluated articles were screened for additional publications meeting the inclusion criteria.

We included controlled trials and observational studies involving patients with MS and spasticity of any degree. Studies in non-English languages, using non-validated or not specified outcome measures were excluded, as well as those studies involving patients with spasticity not due to MS (unless MS patients were at least half of the sample).We extracted information regarding efficacy and side-effects for each of the selected interventions.

Scientific evidence for antispasticity treatments was evaluated according to prespecified levels of certainty (class I, II, III, and IV). ${ }^{12}$ Due to the universal scope of this review, local issues such as costs and drug licensing were not taken into account when offering advice on use in clinical practice. Two independent investigators (SO and JS) evaluated the quality of evidence and wrote the initial draft that was evaluated by the chairman (XM) and circulated to the rest of the authors for further input, discussion and final agreement. 


\section{RESULTS}

\section{Centrally acting oral muscle relaxants}

\section{Oral baclofen}

Oral baclofen is a structural analogue of gamma-aminobutyric acid (GABA) which crosses the blood-brain barrier and binds to pre- and postsynaptic GABA receptors, decreasing activity in motoneurons and interneurons. Control of symptoms is usually obtained with doses up to $60 \mathrm{mg}$, with a maximum daily dose of $100 \mathrm{mg} .{ }^{13}$ Twelve controlled trials were identified and, after exclusion of two studies (lack of outcome description $^{14}$ and non-English language ${ }^{15}$ ), nine randomized ${ }^{16-24}$ and one nonrandomized $^{25}$ controlled trials met the inclusion criteria. Of these, seven were placebocontrolled trials ${ }^{16 ; 18 ; 20 ; 21 ; 23 ; 24 ; 25}$ and three were comparations with diazepam ${ }^{17 ; 19 ; 22}$. Six out of the 7 placebo-controlled studies ${ }^{16 ; 18 ; 20 ; 23 ; 24 ; 25}$ showed a statistically significant improvement on spasticity when on baclofen compared with placebo, and one study, with a lower sample size, reported no differences ${ }^{21}$ (class II/III evidence). Baclofen also improved the frequency of spasms and clonus ${ }^{18 ; 23}$ (class III evidence).

None of the three studies comparing baclofen and diazepam showed significant differences using the Ashworth or similar scales. ${ }^{17 ; 19 ; 22}$ Similarly, there were no differences in the effect on the frequency of spasms between the two drugs ${ }^{19 ; 22}$ (class III evidence). One of these trials compared high versus low doses of baclofen (30 or $60 \mathrm{mg}$ ) and diazepam (15 or $30 \mathrm{mg}) .{ }^{17}$ While both doses showed a significant change in the Ashworth score before and after treatment, there was a marked improvement in those patients able to tolerate high doses (class III evidence). 
In the majority of the analysed trials, baclofen showed an improvement in spasticity compared to placebo, with no differences compared to diazepam. However, the small size of the trials and the heterogeneity in the outcomes must be taken into account. Side effects, such as drowsiness, weakness, paresthesia, and dry mouth were common (10 to $75 \%)$ and limited the maximum tolerated dose, but they were fewer and better tolerated than those caused by diazepam. ${ }^{26}$

\section{Tizanidine}

Tizanidine is a short-acting muscle relaxant which stimulates the central alpha2adrenergic receptors, leading to a reduced release of excitatory neurotransmitters at spinal and supraspinal levels. It is usually started at a dose of $2 \mathrm{mg}$ daily, increased up to a maximum dose of $36 \mathrm{mg}$ daily with an average effective dose between $12 \mathrm{mg}$ and 24mg. ${ }^{27}$ Thirteen trials met the inclusion criteria; two evaluating tizanidine in single dose compared with placebo ${ }^{28 ; 29}$ and 11 assessing the medium-term use of the drug (515 weeks) compared with placebo ${ }^{30-33}$, with diazepam ${ }^{34}$ or with baclofen ${ }^{35-40}$.

The two single dose studies ${ }^{28 ; 29}$ showed significant dose-dependent improvement using the Pendulum test, but only the larger trial, involving 142 patients, showed an effect on the muscle tone (Class II evidence). The medium-term studies performed in the UK (187 patients) ${ }^{33}$ and USA (220 patients) ${ }^{31}$ evaluated treatment with tizanidine (titrated from 2 and $36 \mathrm{mg}$ daily) compared to placebo over a 12 week period, using the Ashworth score. The UK study reported a significant reduction in muscle tone with tizanidine, while the USA study found no differences between groups. Both studies showed a greater, but nonsignificant, reduction in spasms and clonus in the treated group (class I evidence). It should be noted that the baseline muscle tone in the USA 
study was slightly higher in the placebo group and its decrease was greater than expected.

In an additional placebo-controlled parallel trial (2-week washout period and a 3-week titration phase to a maximum dose of $32 \mathrm{mg}$ per day) involving $66 \mathrm{MS}$ patients, tizanidine showed a beneficial effect on spasticity without significant differences in the neurological status (Expanded Disability Status Scale-EDSS-) ${ }^{32}$ (class I evidence). In a further trial, testing sublingual and oral routes of administration, both had a positive effect compared to placebo in muscle tone, with no differences in walking speed (Timed 25-Foot Walk test) or fatigue (Fatigue Severity scale score). Sublingual tizanidine showed a significant reduction in the next-day somnolence (modified Epworth sleepiness scale $)^{30}$ (class II evidence).

When compared with baclofen or diazepam, tizanidine showed a similar positive effect with no statistical difference between treatment groups. Several outcomes were considered, such as muscle tone, frequency of spasms and clonus, neurological disability, functional disability, physician's assessment of clinical change and patient's subjective perception (class II evidence) $)^{34-40}$.

In summary, tizanidine was superior in the short and medium term compared to placebo and equally effective compared to diazepam or baclofen. Side effects (mainly related to its alpha2-adrenergic activity including drowsiness and dry mouth) were dose-related. Decreases in blood pressure and heart rate were also reported, as well as transient increases in hepatic transaminase levels, with normalization following discontinuation of treatment. ${ }^{41}$ 


\section{Benzodiazepines}

Diazepam enhances the effect of the neurotransmitter GABA and suppresses neuronal activity in the reticular formation, contributing to muscle relaxation. The maximum recommended dose is $30 \mathrm{mg}$ per day, with an average dose of $15 \mathrm{mg} .{ }^{10}$ In the initial search, eight trials were identified and the only placebo-controlled trial ${ }^{42}$ was excluded (only 4 out of 21 patients had MS). The remaining studies used baclofen ${ }^{17 ; 19 ; 22}$, tizanidine ${ }^{34}$, dantrolene ${ }^{43}$ and ketazolam. ${ }^{44 ; 5}$ as active comparators.

As described previously, both diazepam and baclofen showed a positive effect on spasticity with a similar safety profile, despite more sedation observed with diazepam

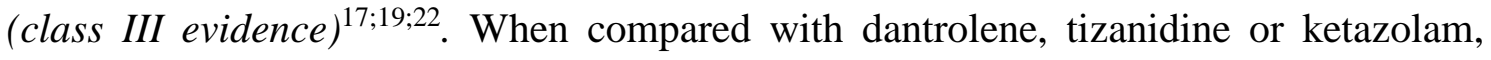
diazepam also produced a similar reduction in spasticity (class II/III evidence $)^{34 ; 43 ; 44 ; 45}$.

\section{Gabapentin}

Gabapentin is structurally similar to GABA, exerting GABAergic activity by binding receptors in the neocortex and hippocampus. The normal starting dose is $300 \mathrm{mg}$ per day escalated up to a maximum daily dose of $3600 \mathrm{mg} .{ }^{46}$ Five studies were identified and three were excluded for methodological reasons (open-label trials ${ }^{47 ; 48}$ and case report $\left.{ }^{49}\right)$. The analysed studies were randomized, placebo-controlled short-duration crossover trials. ${ }^{50 ; 51}$ The higher dose study ${ }^{50}$ (up to $900 \mathrm{mg}$ gabapentin orally three times daily over a 6-day period) reported a significant effect in all physician-assessed measures and subject-reported outcomes. The lower dose study ${ }^{51}$ (400 mg gabapentin orally three times daily for 48 hours) also reported a decrease in the modified Ashworth score, but no effect on clonus, reflexes or response to noxious stimuli (Class II 
evidence). The main adverse effects were drowsiness, somnolence and dizziness but it was generally well tolerated, with no serious side effects reported. ${ }^{50 ; 51}$

Considering this evidence regarding centrally acting oral muscle relaxants, several practical recommendations can be made. In patients who experience spasticity, baclofen could be considered as one of the first treatment options. Due to the potential risk of dose related side effects, treatment should be initiated at low dose (5-10 mg daily) and gradually titrated upwards to a maximum of $100 \mathrm{mg}$ per day. ${ }^{13}$ Tizanidine may also be used as an alternative to baclofen, given the similarities in efficacy and global tolerability between both drugs. Dose related side effects and individual variation in the tolerated dose prove the need to start tizanidine at $2 \mathrm{mg}$ daily and slowly increase to a maximum of $36 \mathrm{mg}$. Given the risk of hepatic dysfunction, present recommendations include monitoring of liver function monthly for the first six months of treatment and periodically thereafter. ${ }^{52}$ Gabapentin can be an alternative to baclofen and tizanidine, based on its clinical effect and safety profile, but no head to head comparations between gabapentine and other drugs are available. In light of the higher risk of side effects, diazepam could be considered in patients where no clinical improvement is seen with oral baclofen, tizanidine or gabapentin. The authors of this document agree that a stepwise approach to therapy favouring monotherapy is preferred to a combination of drugs. As inclusion criteria are not homogeneous in the available studies, the general indication would be to start treatment if there is interference with activities of daily living (basic and/or instrumental) or if the patient suffers from significant pain. See figure 1 for spasticity treatment algorithm. 


\section{Peripherally acting oral muscle relaxants}

\section{Dantrolene}

Dantrolene acts on the contractile mechanism of skeletal muscle, decreasing the release of calcium. Treatment regimes are usually started at $25 \mathrm{mg}$ once daily and increased gradually to a maximum of $400 \mathrm{mg}$ divided into four doses. ${ }^{53}$ Six studies were identified and three were excluded (open trial design ${ }^{54}$ or MS patients representing less than half of the study sample $\left.{ }^{55 ; 56}\right)$.

Two small studies, a crossover (20 patients) ${ }^{57}$ and a parallel-group trial (23 patients $)^{58}$, compared dantrolene with placebo, starting at $50 \mathrm{mg}$ or $25 \mathrm{mg}$ four times a day, respectively, and titrated to a maximum of $100 \mathrm{mg}$. The crossover trial only provided patients' preferences (35\% chose dantrolene over placebo, 20\% preferred placebo and $45 \%$ had no preference $)^{57}$ (class III evidence). In the parallel-group study, a reduction in a spasticity semi-quantitative scale was observed in $42 \%$ of patients on dantrolene, and $27 \%$ on placebo $^{58}$ (class III evidence).

A later trial compared dantrolene versus diazepam using a fixed increasing dosage schedule over a two-week period, followed by another 2 weeks of maximum dose ${ }^{43}$. Both dantrolene and diazepam reduced spasticity and reflexes at low and high doses, but this reduction was significantly greater with dantrolene at higher doses. Subjective improvement was reported for two categories (muscle spasms or cramps and stiffness) with no statistical difference between drugs (Class II evidence).

Dantrolene proved superior to placebo using objective and subjective measures, based on low quality evidence. The usage of dantrolene is restricted due to the frequency of 
side effects, such as gastrointestinal symptoms, weakness, fatigue, sedation and dizziness. The risk of hepatotoxicity is the major limitating factor and requires monitoring of liver function prior and during therapy. ${ }^{53,59}$ As a consequence, the evidence would support the use of dantrolene only in patients where no clinical improvement is seen with oral baclofen, tizanidine or gabapentin (see figure 1 for spasticity treatment algorithm). Given that weakness is a frequent side effect, dantrolene may be reserved for non-ambulatory patients.

\section{Cannabis-based drugs}

Several pharmacological products with cannabinoid-receptor mediated effects containing D9-THC and cannabidiol (CBD) or synthetic D9-THC (dronabinol) are now available. ${ }^{60}$ We identified 13 studies involving cannabis-based drugs for the treatment of spasticity in MS. Four were excluded ( observational studies ${ }^{61 ; 62}$ a preliminary trial, ${ }^{63}$ or MS patients representing less than half of the sample ${ }^{64}$ ) A total of 8 randomized placebo-controlled studies ${ }^{65-72}$ and one metaanalysis ${ }^{73}$ were considered.

The first available studies were a crossover trial using low doses of dronabinol (Marinol®) or a $C$ sativa plant extract ${ }^{66}$; a large multicenter placebo-controlled trial (CAMS study, UK) using oral cannabis extract, delta9-tetrahydrocannabinol or placebo over 15 weeks $^{71}$ (and its subsequent follow-up study during 12 months $^{72}$ ); and a singlecentre placebo-controlled crossover study of cannabis-extract capsules containing tetrahydrocannabinol (THC) and cannabidiol (CBD). ${ }^{69}$ They all used the mean change in the Ashworth score, showing no significant change at the end of the treatment period (class II evidence). However, they showed a significant improvement in spasticity, pain, 
sleep disruption or spasms using self-completion questionnaires ${ }^{66 ; 69 ; 71}$ (class II evidence). A significant treatment effect in the timed 10-meter Walk Test at 15 weeks (available for 278 out of the 630 patients) was seen in the CAMS study, but was no longer significant in the 12 month follow-up ${ }^{72}$ (class II evidence).

Nabiximols (Sativex ${ }^{\circledR}$ ) is an oromucosal spray of cannabis extract containing THC and cannabidiol. Therapy usually starts with a 2-week dose titration phase up to a maximum daily dose of 12 sprays. ${ }^{74}$ Nabiximols was initially tested against placebo in MS patients with a variety of symtoms (spasticity, spasms, bladder problems, tremor or pain) evaluating the change in the Visual Analogue Score of their most troublesome symptom. ${ }^{70}$ Patients on active treatment and spasticity showed a significant reduction in their Visual Analogue Score that could not be confirmed with the Ashworth scale (class I evidence). The Numeric Rating Scale was used as primary outcome in two further trials showing a significant improvement and highlighting the difference in the proportion of responders (defined as $\geq 30 \%$ reduction on the Numeric Rating spasticity score) between the nabiximols and placebo groups ${ }^{75 ; 76}$ (class I evidence). These three trials were combined in a meta-analysis, including 666 patients, that confirmed the overall eficacy of nabiximols. ${ }^{73}$

To overcome the possible underestimation of drug efficacy in previous studies, a recent trial used an enriched study design, selecting responders (at least $20 \%$ reduction in mean Numeric Rating score) in a single-blind study phase. ${ }^{68}$ These patients were subsequently randomized in a double blinded phase to nabiximols or placebo over a 12 week period with a resulting significant superiority of nabiximols over placebo 
according to the Numeric Rating Spasticity Scale. Nabiximols also had a better impact on spasm frequency, sleep disruption and the Barthel Scale ${ }^{68}$ (class I evidence).

Finally, in a 5-week withdrawal study, patients on long-term treatment with nabiximols were blindly randomized to nabiximols or placebo. ${ }^{67}$ Treatment failure (defined as either cessation of treatment, $20 \%$ increase in spasticity, or taking additional medication) was present in $94 \%$ subjects from the placebo group compared to $44 \%$ in the nabiximols group. The time to treatment failure significantly favoured nabiximols (class I evidence).

In summary, nabiximols showed a positive effect without serious adverse events in recent high class trials with an enriched study design, where it was used as an add-on therapy. However, there was an increased incidence of non-serious adverse events, with dizziness the most frequently reported. ${ }^{77}$ This evidence would support its use in MS patients with spasticity and a suboptimal therapeutic response or poor tolerance to oral drugs (baclofen, tizanidine and gabapentin) (See figure 1 for spasticity treatment algorithm). The therapeutic response must be evaluated after 4 weeks, as only less than $50 \%$ of patients are responders, and discontinuation should be considered if no significant symptom improvement is seen. It is noteworthy that an influential review by NICE in the $\mathrm{UK}^{78}$ accepted the data on nabiximols in terms of efficacy and safety. Their final recommendation that the drug not be used was made solely on grounds of its not meeting cost-efficacy requirements. We are aware that access to, and reimbursement of this drug, varies among healthcare systems more than others reviewed. 


\section{Peripherally acting injected muscle relaxants}

\section{Botulinum toxin}

Botulinum toxin type A blocks release of acetylcholine at neuromuscular junctions inhibiting muscle contraction. Local injection of botulinum toxin A in isolated muscles has a lasting effect over several weeks with complete reversibility. ${ }^{79}$ Five studies were identified in the initial search and three were excluded (case-series design, ${ }^{80} \mathrm{MS}$ patients representeing less than half of the sample ${ }^{81}$ and open-label uncontrolled $\left.\operatorname{design}^{82}\right)$.

Two placebo-controlled randomized trials were available. ${ }^{83 ; 84}$ Botulinum toxin (400 MU) tested in 10 chair-bound or bed-bound patients decreased the spasticity score and eased patient care ${ }^{83}$ (class III evidence). The other trial evaluated three treatment arms (500, 1000 and 1500 MU) versus placebo on hip adductor spasticity.The modified Ashworth scale and spasm frequency improved to a similar extent in all four groups, but significant changes were only observed in muscle tone for the botulinum toxin groups. Time to re-treatment was significantly longer for all treatment doses compared with placebo (class I evidence). ${ }^{84}$

Only two trials evaluated Botulinum toxin in MS, involving a small number of patients over a short period of time. Nevertheless, the observed effects and the safety profile (similar to placebo with the exception of muscle weakness ${ }^{84}$ ), would support the use of local application of botulinum toxin A in patients with MS and focal spasticity of the lower limbs (see figure 1 for spasticity treatment algorithm). Botulinum toxin injection demands excellent knowledge of anatomy and function and physicians offering the treatment should be trained in its use. ${ }^{79}$ 


\section{Local phenol injections}

Phenol injected in motor points of selected muscles leads to axonal damage. Solutions between $5-8 \%$ phenol produce a selective effect, that can be maximized by combining phenol with glycerin which limits its spread. ${ }^{85}$ No randomized controlled trials were identified evaluating the effect of phenol injections on spasticity due to MS or other causes. Given the lack of higher grade evidence, case series and observational studies were considered. Four studies were identified and two were excluded (lack of adequate description of the study population ${ }^{86}$ and not adressing the topic of interest ${ }^{87)}$. The remaining two studies were a case series ${ }^{88}$ and a prospective study. ${ }^{89}$

The case series included 69 patients reporting a general relief of spasticity lasting from 3 to 14 months in the majority of patients (class IV evidence). ${ }^{88}$ The prospective study included 62 patients followed over three months after phenol injection showing a significant reduction in the spasticity of hip adductors after the first week, with a maximum improvement after the first month. An important increase in the range of motion values for hip abduction was observed (class IV evidence). ${ }^{89}$

The evidence supporting the use of phenol injections for the treatment of spasticity is limited and of very low quality. Nevertheless, these studies showed a positive effect in reducing spasticity, spasms and pain in a high proportion of patients. Adverse effects were uncommon and temporary, with dysesthesia the most frequently reported. Therefore, phenol injections could be considered as an alternative to botulinum toxin in the management of focal spasticity, but higher quality evidence is needed to fully support its use. 


\section{Intrathecal therapies}

\section{Intrathecal baclofen}

Since baclofen does not cross the blood-brain barrier effectively, intrathecal administration achieves much higher concentrations in the cerebrospinal fluid. A surgically implanted pump with reservoir allows four times the concentration of drug at $1 \%$ of the oral dosage. Pump implantation is considered only after testing responsiveness and optimal individual doses. Treatment is started at a dose of $25 \mu \mathrm{g}$ per day, increasing over the first 6 months up to an average of 400 to $500 \mu \mathrm{g}$ daily. ${ }^{46}$

Three randomized-controlled trials met the inclusion criteria ${ }^{90-92}$ and all examined the effect of baclofen administered intrathecally by a programmable infusion pump after an initial screening stage to test responsiveness. In a long-term multicentre placebocontrolled trial including 22 patients, the active treatment group showed a significant improvement in the Ashworth score, the spasms score and the self-reported pain score (class I evidence) ${ }^{91}$. These results were confirmed in a larger multicentre trial $^{90}$ (class III evidence) and in a short-term placebo-controlled crossover trial ${ }^{92}$ (class II evidence).

Intrathecal baclofen appears to show a beneficial clinical effect in patients with severe spasticity, accepting some limitations in the analysed studies including a failure to justify the sample sizes and a lack of published direct head-to-head comparisons. Side effects caused by the drug itself are uncommon, being drowsiness, dizziness, blurred vision and slurred speech the most frequently reported. Technical complications include those related to the surgical procedure, dysfunction of the pump and catheter-related issues. ${ }^{90 ; 93}$ The implantation of an intrathecal baclofen pump to relieve lower limb 
spasticity could be considered if suboptimal response to oral drugs is observed. Prior to implantation, its efficacy must be evaluated by way of an intrathecal baclofen test and, in patients with walking ability this test must be performed using an external pump which allows the functional performance of the patient to be evaluated ${ }^{94}$. The authors of this document agree that a careful selection of patients based on the identification of realistic and mutually agreed treatment goals is recommended.

\section{Intrathecal phenol}

No randomized controlled trials evaluating the effect of intrathecal phenol on spasticity due to MS or other causes were identified and four observational studies were reviewed. ${ }^{95-98}$ Two case series reported descriptive results in terms of general relief of spasticity (class IV evidence). ${ }^{95 ; 96}$ A cross-sectional observational study compared an initial phenol injection (initial group) versus subsequent injections (serial group) in five muscle groups, in both targeted and non-targeted sides, showing a significant reduction in the Ashworth score in both groups. ${ }^{97}$ (class IV evidence). Finally, in a retrospective study, 40 patients treated with intrathecal phenol showed improvement using a simple rating scale and by attainment of rehabilitation goals (class IV evidence). ${ }^{98}$

Evidence supporting the use of phenol intrathecal injections is limited and of very low quality. This drug should be reserved for MS with severe spasticity and suboptimal response to oral drugs who do not show benefit after an intrathecal baclofen test, for which there is larger evidence to support its use. See Figure 1 for spasticity treatment algorithm. 


\section{CONCLUSIONS}

Spasticity is a complex phenomenon resulting in a large inter- and intra-individual variability in the responses to therapeutic interventions. Overall, the methodological quality of the studies described was poor, with small sample sizes and short duration, which limits inference of long-term efficacy. There was also marked heterogeneity in patients' characteristics and treatment regimens. The difficulty in the quantification of spasticity is reflected in the wide variety of approaches taken to assess this symptom and in the global discrepancy between relief of spasticity and improvement of the neurological status. Furthermore, a discrepancy between published evidence and the daily experience of those who manage spasticity was also evident. There is a need for large, well-designed trials with better assessment tools that incorporate functional ability and patient's quality of life, to confirm the effectiveness of the widely used antispasticity agents.

Funding: None.

This paper has received the endorsement of the European Committee for Treatment and Research in Multiple Sclerosis (ECTRIMS) 


\section{Reference List}

1. Rizzo MA, Hadjimichael OC, Preiningerova J, Vollmer TL. Prevalence and treatment of spasticity reported by multiple sclerosis patients. Mult.Scler. 2004;10:589-95.

2. Biering-Sorensen F, Nielsen JB, Klinge K. Spasticity-assessment: a review. Spinal Cord. 2006;44:708-22.

3. Haselkorn JK, Balsdon RC, Fry WD, Herndon RM, Johnson B, Little JW, Miller JR, Rosenberg JH, Seidle ME. Overview of spasticity management in multiple sclerosis. Evidence-based management strategies for spasticity treatment in multiple sclerosis. $J$ Spinal Cord.Med 2005;28:167-99.

4. Platz T, Eickhof C, Nuyens G, Vuadens P. Clinical scales for the assessment of spasticity, associated phenomena, and function: a systematic review of the literature. Disabil.Rehabil. 2005;27:7-18.

5. Haugh AB, Pandyan AD, Johnson GR. A systematic review of the Tardieu Scale for the measurement of spasticity. Disabil.Rehabil. 2006;28:899-907.

6. Priebe MM, Sherwood AM, Thornby JI, Kharas NF, Markowski J. Clinical assessment of spasticity in spinal cord injury: a multidimensional problem. Arch.Phys.Med.Rehabil. 1996;77:713-6.

7. Hobart JC, Riazi A, Thompson AJ, Styles IM, Ingram W, Vickery PJ, Warner M, Fox PJ, Zajicek JP. Getting the measure of spasticity in multiple sclerosis: the Multiple Sclerosis Spasticity Scale (MSSS-88). Brain 2006;129:224-34.

8. Syczewska M, Lebiedowska MK, Pandyan AD. Quantifying repeatability of the Wartenberg pendulum test parameters in children with spasticity. J.Neurosci.Methods 2009;178:340-4. 
9. Thompson AJ, Jarrett L, Lockley L, Marsden J, Stevenson VL. Clinical management of spasticity. J.Neurol.Neurosurg.Psychiatry 2005;76:459-63.

10. Lapeyre E, Kuks JB, Meijler WJ. Spasticity: revisiting the role and the individual value of several pharmacological treatments. NeuroRehabilitation. 2010;27:193-200.

11. Amatya B, Khan F, La Mantia L, Demetrios M, Wade DT. Non pharmacological interventions for spasticity in multiple sclerosis. Cochrane.Database.Syst.Rev. 2013;2:CD009974.

12. Brainin M, Barnes M, Baron JC, Gilhus NE, Hughes R, Selmaj K, Waldemar G. Guidance for the preparation of neurological management guidelines by EFNS scientific task forces--revised recommendations 2004. Eur.J.Neurol. 2004;11:577-81.

13. Summary of product characteristics: Oral baclofen. http://www.medicines.org.uk/emc/medicine/23850. Accessed on December 2015.

14. Basmajian JV. Lioresal (baclofen) treatment of spasticity in multiple sclerosis. Am J Phys.Med 1975;54:175-7.

15. Jerusalem F. [Double-blind study on the antispastic effect of beta-94-chlorphenyl)gamma aminobutyric acid (CIBA) in multiple sclerosis]. Nervenarzt 1968;39:515-7.

16. Brar SP, Smith MB, Nelson LM, Franklin GM, Cobble ND. Evaluation of treatment protocols on minimal to moderate spasticity in multiple sclerosis. Arch Phys.Med Rehabil. 1991;72:186-9.

17. Cartlidge NE, Hudgson P, Weightman D. A comparison of baclofen and diazepam in the treatment of spasticity. J Neurol Sci 1974;23:17-24. 
18. Feldman RG, Kelly-Hayes M, Conomy JP, Foley JM. Baclofen for spasticity in multiple sclerosis. Double-blind crossover and three-year study. Neurology 1978;28:1094-8.

19. From A, Heltberg A. A double-blind trial with baclofen (Lioresal) and diazepam in spasticity due to multiple sclerosis. Acta Neurol Scand 1975;51:158-66.

20. Hudgson P, Weightman D. Baclofen in the treatment of spasticity. Br.Med J 1971;4:157.

21. Orsnes GB, Sorensen PS, Larsen TK, Ravnborg M. Effect of baclofen on gait in spastic MS patients. Acta Neurol Scand 2000;101:244-8.

22. Roussan M, Terrence C, Fromm G. Baclofen versus diazepam for the treatment of spasticity and long-term follow-up of baclofen therapy. Pharmatherapeutica 1985;4:278-84.

23. Sachais BA, Logue JN, Carey MS. Baclofen, a new antispastic drug. A controlled, multicenter trial in patients with multiple sclerosis. Arch Neurol 1977;34:422-8.

24. Sawa GM, Paty DW. The use of baclofen in treatment of spasticity in multiple sclerosis. Can.J Neurol Sci 1979;6:351-4.

25. Levine IM, Jossmann PB, DeAngelis V. Liorseal, a new muscle relaxant in the treatment of spasticity--a double-blind quantitative evaluation. Dis Nerv.Syst. 1977;38:1011-5.

26. Dario A, Tomei G. A benefit-risk assessment of baclofen in severe spinal spasticity. Drug Saf 2004;27:799-818.

27. Summary of product characteristics: Tizanidine. https://www.medicines.org.uk/emc/medicine/22602 . Accessed on December 2015. 
28. Emre M, Leslie GC, Muir C, Part NJ, Pokorny R, Roberts RC. Correlations between dose, plasma concentrations, and antispastic action of tizanidine (Sirdalud). J Neurol Neurosurg Psychiatry 1994;57:1355-9.

29. Nance PW, Sheremata WA, Lynch SG, Vollmer T, Hudson S, Francis GS, O'Connor P, Cohen JA, Schapiro RT, Whitham R, Mass MK, Lindsey JW, Shellenberger K. Relationship of the antispasticity effect of tizanidine to plasma concentration in patients with multiple sclerosis. Arch.Neurol. 1997;54:731-6.

30. Vakhapova V, Auriel E, Karni A. Nightly sublingual tizanidine $\mathrm{HCl}$ in multiple sclerosis: clinical efficacy and safety. Clin Neuropharmacol. 2010;33:151-4.

31. Smith C, Birnbaum G, Carter JL, Greenstein J, Lublin FD. Tizanidine treatment of spasticity caused by multiple sclerosis: results of a double-blind, placebo-controlled trial. US Tizanidine Study Group. Neurology 1994;44:S34-S42.

32. Lapierre Y, Bouchard S, Tansey C, Gendron D, Barkas WJ, Francis GS. Treatment of spasticity with tizanidine in multiple sclerosis. Can.J Neurol Sci 1987;14:513-7.

33. A double-blind, placebo-controlled trial of tizanidine in the treatment of spasticity caused by multiple sclerosis. United Kingdom Tizanidine Trial Group. Neurology 1994;44:S70-S78.

34. Rinne U. Tizanidine treatment of spasticity in multiple sclerosis and chronic myelopathy. Curr Ther Res Clin Exp 1980;28:827-36.

35. Eyssette M, Rohmer F, Serratrice G, Warter JM, Boisson D. Multi-centre, double-blind trial of a novel antispastic agent, tizanidine, in spasticity associated with multiple sclerosis. Curr.Med Res Opin. 1988;10:699-708. 
36. Hoogstraten MC, van der Ploeg RJ, vd BW, Vreeling A, van Marle S, Minderhoud JM. Tizanidine versus baclofen in the treatment of spasticity in multiple sclerosis patients. Acta Neurol Scand 1988;77:224-30.

37. Newman PM, Nogues M, Newman PK, Weightman D, Hudgson P. Tizanidine in the treatment of spasticity. Eur.J Clin Pharmacol 1982;23:31-5.

38. Rice GP. Tizanidine vs. baclofen in the treatment of spasticity in patients with multiple sclerosis. Can.J Neurol Sci 1989;16:451.

39. Smolenski C, Muff S, Smolenski-Kautz S. A double-blind comparative trial of new muscle relaxant, tizanidine (DS 103-282), and baclofen in the treatment of chronic spasticity in multiple sclerosis. Curr.Med Res Opin. 1981;7:374-83.

40. Stien R, Nordal HJ, Oftedal SI, Slettebo M. The treatment of spasticity in multiple sclerosis: a double-blind clinical trial of a new anti-spastic drug tizanidine compared with baclofen. Acta Neurol Scand 1987;75:190-4.

41. Wagstaff AJ, Bryson HM. Tizanidine. A review of its pharmacology, clinical efficacy and tolerability in the management of spasticity associated with cerebral and spinal disorders. Drugs 1997;53:435-52.

42. Neill RW. Diazepam in the relief of muscle spasm resulting from spinal-cord lesions. Ann Phys.Med 1964;Suppl:33-8.

43. Schmidt RT, Lee RH, Spehlmann R. Comparison of dantrolene sodium and diazepam in the treatment of spasticity. J Neurol Neurosurg Psychiatry 1976;39:350-6.

44. Basmajian JV, Shankardass K, Russell D, Yucel V. Ketazolam treatment for spasticity: double-blind study of a new drug. Arch Phys.Med Rehabil. 1984;65:698-701. 
45. Basmajian JV, Shankardass K, Russell D. Ketazolam once daily for spasticity: doubleblind cross-over study. Arch Phys.Med Rehabil. 1986;67:556-7.

46. Kita M, Goodkin DE. Drugs used to treat spasticity. Drugs 2000;59:487-95.

47. Solaro C, Lunardi GL, Capello E, Inglese M, Messmer UM, Uccelli A, Mancardi GL. An open-label trial of gabapentin treatment of paroxysmal symptoms in multiple sclerosis patients. Neurology 1998;51:609-11.

48. Solaro C, Uccelli MM, Guglieri P, Uccelli A, Mancardi GL. Gabapentin is effective in treating nocturnal painful spasms in multiple sclerosis. Mult.Scler. 2000;6:192-3.

49. Dunevsky A, Perel AB. Gabapentin for relief of spasticity associated with multiple sclerosis. Am J Phys.Med Rehabil. 1998;77:451-4.

50. Cutter NC, Scott DD, Johnson JC, Whiteneck G. Gabapentin effect on spasticity in multiple sclerosis: a placebo-controlled, randomized trial. Arch Phys.Med Rehabil. 2000;81:164-9.

51. Mueller ME, Gruenthal M, Olson WL, Olson WH. Gabapentin for relief of upper motor neuron symptoms in multiple sclerosis. Arch Phys.Med Rehabil. 1997;78:521-4.

52. Kamen L, Henney HR, III, Runyan JD. A practical overview of tizanidine use for spasticity secondary to multiple sclerosis, stroke, and spinal cord injury. Curr.Med Res Opin. 2008;24:425-39.

53. Summary of product characteristics: Dantrolene. https://www.medicines.org.uk/emc/medicine/24339 . Accessed on December 2015.

54. Ladd H, Oist C, Jonsson B. The effect of Dantrium on spasticity in multiple sclerosis. Acta Neurol Scand 1974;50:397-408. 
55. Gambi D, Rossini P, Calenda G, Rossetti S, Longoni A. Dantrolene sodium in the treatment of spasticity caused by multiple sclerosis or degenerative myelopathies: a double-blind, crossover study in comparison with placebo. Curr TherRes Clin Exp 1983;33:835-40.

56. Sheplan L, Ishmael C. Spasmolytic properties of dantrolene sodium: clinical evaluation. Mil.Med. 1975;140:26-9.

57. Gelenberg AJ, Poskanzer DC. The effect of dantrolene sodium on spasticity in multiple sclerosis. Neurology 1973;23:1313-5.

58. Tolosa ES, Soll RW, Loewenson RB. Letter: Treatment of spasticity in multiple sclerosis with dantrolene. JAMA 1975;233:1046.

59. Pinder RM, Brogden RN, Speight TM, Avery GS. Dantrolene sodium: a review of its pharmacological properties and therapeutic efficacy in spasticity. Drugs 1977;13:3-23.

60. Russo E, Guy GW. A tale of two cannabinoids: the therapeutic rationale for combining tetrahydrocannabinol and cannabidiol. Med.Hypotheses 2006;66:234-46.

61. Meinck HM, Schonle PW, Conrad B. Effect of cannabinoids on spasticity and ataxia in multiple sclerosis. J Neurol 1989;236:120-2.

62. Wade DT, Makela PM, House H, Bateman C, Robson P. Long-term use of a cannabisbased medicine in the treatment of spasticity and other symptoms in multiple sclerosis. Mult.Scler. 2006;12:639-45.

63. Wade DT, Robson P, House H, Makela P, Aram J. A preliminary controlled study to determine whether whole-plant cannabis extracts can improve intractable neurogenic symptoms. Clin Rehabil. 2003;17:21-9. 
64. Wissel J, Haydn T, Muller J, Brenneis C, Berger T, Poewe W, Schelosky LD. Low dose treatment with the synthetic cannabinoid Nabilone significantly reduces spasticityrelated pain : a double-blind placebo-controlled cross-over trial. J Neurol 2006;253:1337-41.

65. Collin C, Davies P, Mutiboko IK, Ratcliffe S. Randomized controlled trial of cannabisbased medicine in spasticity caused by multiple sclerosis. Eur.J Neurol 2007;14:290-6.

66. Killestein J, Hoogervorst EL, Reif M, Kalkers NF, Van Loenen AC, Staats PG, Gorter RW, Uitdehaag BM, Polman CH. Safety, tolerability, and efficacy of orally administered cannabinoids in MS. Neurology 2002;58:1404-7.

67. Notcutt W, Langford R, Davies P, Ratcliffe S, Potts R. A placebo-controlled, parallelgroup, randomized withdrawal study of subjects with symptoms of spasticity due to multiple sclerosis who are receiving long-term Sativex(R) (nabiximols). Mult.Scler. 2012;18:219-28.

68. Novotna A, Mares J, Ratcliffe S, Novakova I, Vachova M, Zapletalova O, Gasperini C, Pozzilli C, Cefaro L, Comi G, Rossi P, Ambler Z, Stelmasiak Z, Erdmann A, Montalban X, Klimek A, Davies P. A randomized, double-blind, placebo-controlled, parallel-group, enriched-design study of nabiximols* (Sativex $((\mathrm{R}))$ ), as add-on therapy, in subjects with refractory spasticity caused by multiple sclerosis. Eur.J Neurol 2011;18:1122-31.

69. Vaney C, Heinzel-Gutenbrunner M, Jobin P, Tschopp F, Gattlen B, Hagen U, Schnelle M, Reif M. Efficacy, safety and tolerability of an orally administered cannabis extract in the treatment of spasticity in patients with multiple sclerosis: a randomized, doubleblind, placebo-controlled, crossover study. Mult.Scler. 2004;10:417-24.

70. Wade DT, Makela P, Robson P, House H, Bateman C. Do cannabis-based medicinal extracts have general or specific effects on symptoms in multiple sclerosis? A double- 
blind, randomized, placebo-controlled study on 160 patients. Mult.Scler. 2004;10:43441.

71. Zajicek J, Fox P, Sanders H, Wright D, Vickery J, Nunn A, Thompson A. Cannabinoids for treatment of spasticity and other symptoms related to multiple sclerosis (CAMS study): multicentre randomised placebo-controlled trial. Lancet 2003;362:1517-26.

72. Zajicek JP, Sanders HP, Wright DE, Vickery PJ, Ingram WM, Reilly SM, Nunn AJ, Teare LJ, Fox PJ, Thompson AJ. Cannabinoids in multiple sclerosis (CAMS) study: safety and efficacy data for 12 months follow up. J Neurol Neurosurg Psychiatry 2005;76:1664-9.

73. Wade DT, Collin C, Stott C, Duncombe P. Meta-analysis of the efficacy and safety of Sativex (nabiximols), on spasticity in people with multiple sclerosis. Mult.Scler. 2010;16:707-14.

74. Karst M, Wippermann S, Ahrens J. Role of cannabinoids in the treatment of pain and (painful) spasticity. Drugs 2010;70:2409-38.

75. Farrar JT, Troxel AB, Stott C, Duncombe P, Jensen MP. Validity, reliability, and clinical importance of change in a 0-10 numeric rating scale measure of spasticity: a post hoc analysis of a randomized, double-blind, placebo-controlled trial. Clin Ther. 2008;30:974-85.

76. Fleuren JF, Voerman GE, Erren-Wolters CV, Snoek GJ, Rietman JS, Hermens HJ, Nene AV. Stop using the Ashworth Scale for the assessment of spasticity. J Neurol Neurosurg Psychiatry 2010;81:46-52.

77. Wang T, Collet JP, Shapiro S, Ware MA. Adverse effects of medical cannabinoids: a systematic review. CMAJ. 2008;178:1669-78. 
78. National Clinical Guideline Centre (UK). Multiple Sclerosis: Management of Multiple Sclerosis in Primary and Secondary Care. London: National Institute for Health and Care Excellence (UK), 2014.

79. Pathak MS, Nguyen HT, Graham HK, Moore AP. Management of spasticity in adults: practical application of botulinum toxin. Eur.J.Neurol. 2006;13 Suppl 1:42-50.

80. Borg-Stein J, Pine ZM, Miller JR, Brin MF. Botulinum toxin for the treatment of spasticity in multiple sclerosis. New observations. Am.J.Phys.Med.Rehabil. 1993;72:364-8.

81. Grazko MA, Polo KB, Jabbari B. Botulinum toxin A for spasticity, muscle spasms, and rigidity. Neurology 1995;45:712-7.

82. Finsterer J, Fuchs I, Mamoli B. Automatic EMG-guided botulinum toxin treatment of spasticity. Clin.Neuropharmacol. 1997;20:195-203.

83. Snow BJ, Tsui JK, Bhatt MH, Varelas M, Hashimoto SA, Calne DB. Treatment of spasticity with botulinum toxin: a double-blind study. Ann Neurol 1990;28:512-5.

84. Hyman N, Barnes M, Bhakta B, Cozens A, Bakheit M, Kreczy-Kleedorfer B, Poewe W, Wissel J, Bain P, Glickman S, Sayer A, Richardson A, Dott C. Botulinum toxin (Dysport) treatment of hip adductor spasticity in multiple sclerosis: a prospective, randomised, double blind, placebo controlled, dose ranging study. J Neurol Neurosurg Psychiatry 2000;68:707-12.

85. Wood KM. The use of phenol as a neurolytic agent: a review. Pain 1978;5:205-29.

86. Copp EP, Harris R, Keenan J. Peripheral nerve block and motor point block with phenol in the management of spasticity. Proc R.Soc.Med 1970;63:937-8. 
87. Wassef MR. Interadductor approach to obturator nerve blockade for spastic conditions of adductor thigh muscles. Reg Anesth. 1993;18:13-7.

88. Awad EA. Phenol block for control of hip flexor and adductor spasticity. Arch Phys.Med Rehabil. 1972;53:554-7.

89. Akkaya T, Unlu E, Alptekin A, Gumus HI, Umay E, Cakci A. Neurolytic phenol blockade of the obturator nerve for severe adductor spasticity. Acta Anaesthesiol.Scand. 2010;54:79-85.

90. Coffey JR, Cahill D, Steers W, Park TS, Ordia J, Meythaler J, Herman R, Shetter AG, Levy R, Gill B, . Intrathecal baclofen for intractable spasticity of spinal origin: results of a long-term multicenter study. J Neurosurg 1993;78:226-32.

91. Middel B, Kuipers-Upmeijer H, Bouma J, Staal M, Oenema D, Postma T, Terpstra S, Stewart R. Effect of intrathecal baclofen delivered by an implanted programmable pump on health related quality of life in patients with severe spasticity. J.Neurol.Neurosurg.Psychiatry 1997;63:204-9.

92. Penn RD, Savoy SM, Corcos D, Latash M, Gottlieb G, Parke B, Kroin JS. Intrathecal baclofen for severe spinal spasticity. N.Engl.J.Med. 1989;320:1517-21.

93. Penn RD. Intrathecal baclofen for spasticity of spinal origin: seven years of experience. J Neurosurg 1992;77:236-40.

94. Intrathecal baclofen pump for spasticity: an evidence-based analysis. Ont.Health Technol.Assess.Ser. 2005;5:1-93.

95. Browne RA, Catton DV. The use of intrathecal phenol for muscle spasms in multiple sclerosis. A description of two cases. Can.Anaesth.Soc.J 1975;22:208-18. 
96. Cain HD. Subarachnoid phenol block in the treatment of pain and spasticity. Paraplegia 1965;3:152-60.

97. Jarrett L, Nandi P, Thompson AJ. Managing severe lower limb spasticity in multiple sclerosis: does intrathecal phenol have a role? J Neurol Neurosurg Psychiatry 2002;73:705-9.

98. Pinder C, Bhakta B, Kodavali K. Intrathecal phenol: an old treatment revisited. Disabil.Rehabil. 2008;30:381-6.

99. Clinical practice guideline on the management of people with multiple sclerosis. Catalan Health Agency for Quality and Assessment (AQuAS), Multiple Sclerosis Center of Catalonia (Cemcat), coordinators. Barcelona: AQuAS.Departament de Salut.Generalitat de Catalunya, 2012.

\section{Figure 1. Spasticity treatment algorithm}

1. Using validated scoring systems to determine the level of spasticity and evaluation of its impact on functioning. It is important to evaluate the beneficial and/or harmful effects of spasticity from a functional perspective as it is not always a disabling symptom/sign. In some cases, spasticity may have beneficial effects and improve the performance status of the patient.

2. Specific treatment of the aggravating factor (ie. antibiotics for urinary infection).

Adapted from: Clinical practice guideline on the management of people with Multiple Sclerosis ${ }^{99}$ 



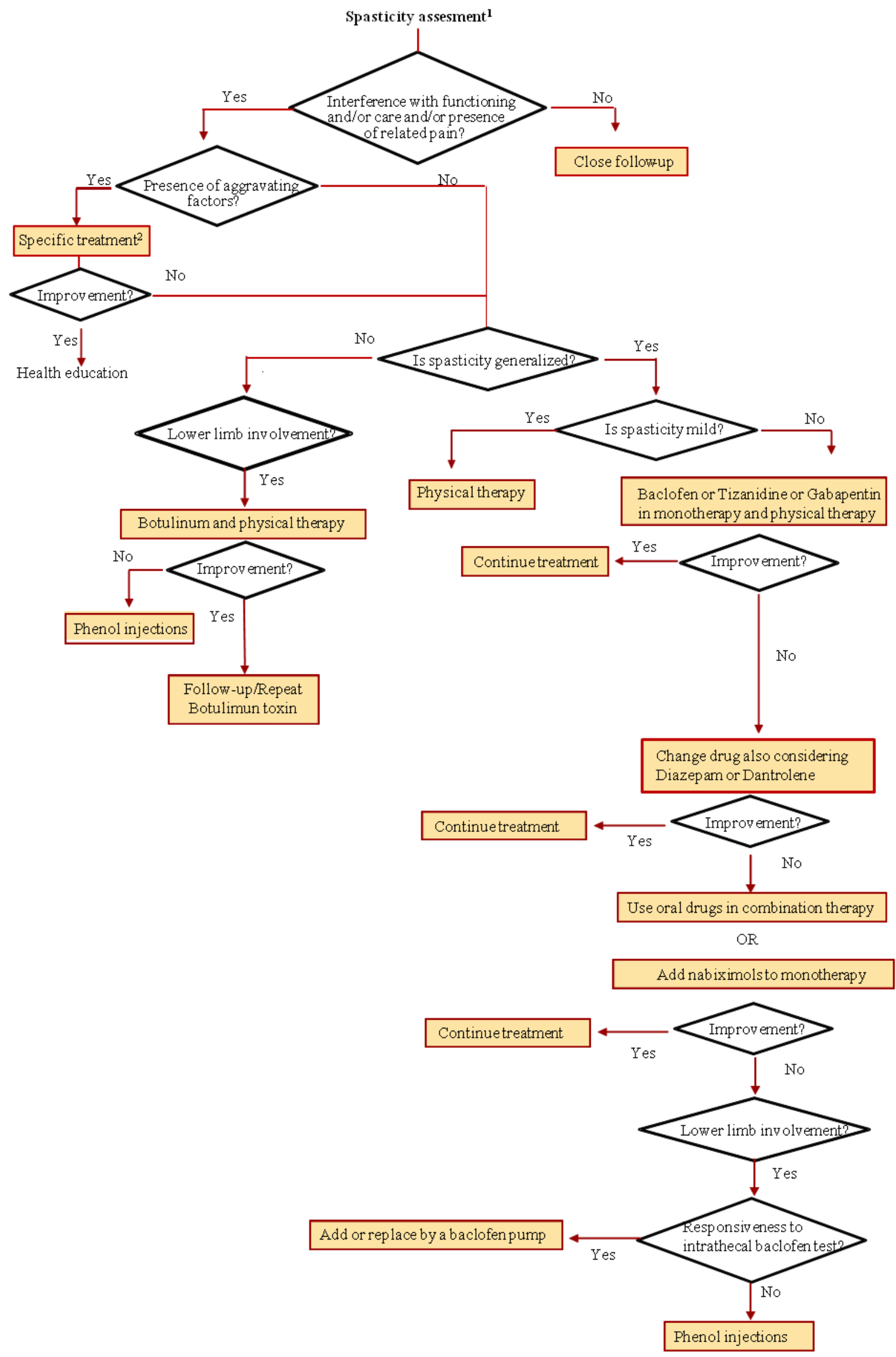


